\title{
Conselho de Escola: funçóes, problemas e perspectivas na gestão escolar democrática
}

\author{
Ângelo Ricardo de Souza*
}

\section{Resumo:}

O artigo, de natureza bibliográfica, discute os problemas e as perspectivas democráticas dos conselhos de escola. O trabalho discute inicialmente o problema da mitificação da técnica na constituição e uso de mecanismos organizativos de gestão escolar. Na seqüência, o texto demonstra como as funções e potencialidades democráticas do conselho de escola são contrapostas às dificuldades cotidianas para a constituição, manutenção e desenvolvimento de espaços coletivos de gestão, demonstrando o quanto os conselhos são, em princípio, espaços do diálogo e, ao mesmo tempo, o quão distante estão da efetivação da sua função democrática. As conclusões apontam para o importante reconhecimento dos limites existentes na formulação e organização dos conselhos de escola, mas, ao mesmo tempo, sugerem a necessidade da insistência na manutenção e aperfeiçoamento dos conselhos por representarem uma contribuição significativa para a gestão escolar democrática.

Palavras-chave: Conselhos de educação. Escolas - Organização e administração.

* Doutor em Educação pela PUC-SP. Professor do Núcleo de Políticas, Gestão e Financiamento da Educação (NuPE) e do Programa de Pós-Graduação em Educação da Universidade Federal do Paraná. 


\section{Introdução}

Este estudo discute as funções e a extensão dos problemas que se apresentam na constituição e funcionamento dos conselhos de escola. A ausência de determinadas vozes na conjunção de esforços para a definição dos rumos da gestão escolar e a necessidade da presença de outros sujeitos com vistas a se compor um quadro multirreferenciado, necessário ao enfrentamento à crescente complexidade dos problemas escolares, sustentam os argumentos em favor da constituição e incremento dos conselhos de escola, instituições que devem contar com a presença de representantes de todos os segmentos escolares, conforme atesta a LDB, no artigo 14, II (BRASIL, 1996). ${ }^{1}$

Contudo, pesquisas empíricas sobre o funcionamento dos conselhos (PINTO, 1994; CAMARGO, 1997) avaliam que o seu potencial comunicativo e democrático encontra barreiras, em especial na compreensão que os diferentes sujeitos têm em relação aos princípios e capacidades deste organismo coletivo, na qual há uma identificação do conselho como organismo auxiliar da direção e/ou da gestão escolar.

$\mathrm{O}$ artigo apresenta em dois itens os seus argumentos. Na primeira parte, discute brevemente o problema do mito da técnica dos instrumentos de organização e gestão democrática da escola, o que acaba por resumir os conselhos de escolas em instituições cartorárias (NUNES, 1999). No segundo item, as funções e potencialidades democráticas do conselho de escola são contrapostas ao duro enfrentamento das dificuldades cotidianas para a constituição, manutenção e ampliação de espaços coletivos de gestão, demonstrando o quanto os conselhos são, em princípio, espaços do diálogo e, ao mesmo tempo, o quão distante estão da efetivação da sua função democrática.

\section{Instrumentos da gestão escolar: entre a técnica e a democracia}

A constituição de conselhos de escola e de outros procedimentos mais participativos na gestão escolar articula-se, de um lado, à crescente complexidade dos problemas educacionais e escolares que exige a elaboração de formas mais qualificadas de gestão escolar, desde longa data (TEIXEIRA, 1961, p. 84), e, de outro, aos reclames por maior democracia. Mas até que ponto esses instrumentos verdadeiramente cumprem essas demandas e não 
são apenas elementos técnicos que até mesmo falseiam o objeto e objetivo de uma gestão escolar democrática e de qualidade? O desenvolvimento de instrumentos técnicos de gestão escolar, fruto do avanço científico, tão reclamado nessa área pelos seus precursores no Brasil, bem como a constituição de espaços mais abertos para a participação popular, por vezes parecem se tornar mitos, isto é, parecem encontrar a razão de ser em si mesmos.

Curiosamente, os desenvolvimentos técnico e político que ajudam o desenvolvimento humano, que permitem a sua realização, são os mesmos que submetem o humano às normas e procedimentos instituídos com a intenção de servir ao próprio humano, e isso leva a uma perda no foco da razão da ação (foco este que é o próprio homem), uma vez que procura promover a adaptação ou a repressão.

É contraditório, mas a ciência e a política voltadas ao incremento da vida individual e social e que permitem a superação das respostas mitológicas aos fenômenos da vida e do mundo, ao mesmo tempo são responsáveis pela regressão ao mito ao "tecnificar", "cientificizar" as respostas aos diferentes problemas humanos, enfatizando a forma e deslocando-se do conteúdo.

A ciência e a política, ao se direcionarem para a técnica/forma/ meio, mitifica-a, pois a coloca acima do objeto para o qual a técnica/ forma/meio foi criada, ou ao qual está (ou deveria estar) atrelada e, dessa forma, transforma a forma em conteúdo, elevando-a a posição de verdade absoluta, de mito que responde a tudo (ADORNO; HORKHEIMER, 1985). O indivíduo é colocado pela ciência e pela política como o sujeito a ser adaptado ao seu objeto, que não existe mais, uma vez que substituído pela técnica, logo a repressão que a ciência e a política promovem é a repressão da submissão do indivíduo à técnica/forma.

Nesse sentido, a criação de instituições que tecnificam o diálogo, normatizando-o, organizando em excesso a participação das pessoas através dos seus procedimentos formais, é um procedimento político voltado a direcionar a disputa pelo poder na escola nos moldes como classicamente ela é colocada. Assim, essas instituições acabam não alcançando objetivos mais democráticos verdadeiramente.

A face técnica quando oposta à função política dos instrumentos de gestão agrava esses problemas quando pensa o humano como 
recurso da gestão escolar (RIBEIRO, 1952), pois para esta perspectiva a efetivação de uma gestão escolar qualificada demanda observar e organizar-se os meios distintos em três agrupamentos: os humanos, os legais e os materiais (RIBEIRO, 1952, p. 132). Quando as pessoas deixam de ser o fim de uma atividade humana e passam a ser recurso para esta atividade, definitivamente parece que o que havia de humano na atividade desapareceu, "tecnificou-se".

Em sentido oposto, outros autores compreendem a administração como um fenômeno que opera com o trabalho humano coletivo, mas tendo o homem sempre como o fim das ações: "não parto do homem como recurso, como meio, mas essencialmente como fim. Considerar o homem como fim implica tê-lo como sujeito e não como objeto do processo em que se busca a realização de objetivos." (PARO, 1988, p. 25). Aquela atitude, ao colocar o homem na condição de recurso, também o reduz no sentido de que menos humano ele se torna, passando a ser apenas mais um insumo a ser controlado. E, assim como a técnica na ciência e na política, a técnica da administração, quando assim age, faz regredir o homem à sua condição de natureza, de objeto, não o reconhecendo como ser produtor e fruto da sua própria cultura.

Isso não significa que não haja aspectos técnicos que não devam ser dominados. Tanto ao contrário, a coordenação da política escolar, tarefa principal da gestão escolar (SOUZA, 2007), exige o controle da técnica sobre a qual trabalha, especialmente a técnica pedagógica, elemento central no trabalho escolar. A política necessita da competência técnica, seja para manter o poder nas bases sobre as quais atua, seja para transformá-lo. Um problema que emerge disso é a acomodação da relação entre a direção da política escolar e a competência técnica, representada na burocracia, quando esta parece, segundo Teixeira (1999, p. 140), ganhar vida própria e deixa de estar a serviço da educação pública e aquela se torna patrimonialista e/ ou demagógica.

A constituição de organismos coletivos de gestão se posiciona como pretensa solucionadora desses problemas, mas incorre em um outro problema. Pauta-se na idéia de que a participação das pessoas na gestão da coisa pública é suficiente ou eficiente tecnicamente. Porém, “o colegiado significa quase inevitavelmente [...] um obstáculo às decisões precisas e unívocas e, sobretudo, rápidas.” (WEBER, 2004, p. 222). 
É mal resolvida essa relação entre a eficiência e eficácia com a democracia quando esta é compreendida apenas como a constituição de espaços e momentos de participação popular nos processos de tomada de decisões:

Ora, sabendo que é característico do homem dar palpite em todo e qualquer assunto do qual tome conhecimento, ao associar-se o maior grau de participação ao maior número de pessoas interferindo no processo, entra-se numa espiral de expectativas impossível de se atender nas organizações, que pouco ou nenhum compromisso tem com qualidade e eficiência. [...]. Uma decisão prejudicial ao grupo, ou simplesmente equivocada, pode ser autorizada por um número imenso de pessoas. (GUTIERREZ; CATANI, 2000, p. 61).

Esse problema pode diminuir, em tese, se a ação coletiva se estende para além das tomadas de decisões, atingindo o controle das ações públicas: "a gestão democrática implica o controle do Estado pela sociedade civil, ou seja, é no envolvimento da comunidade na decisão dos rumos dos serviços oferecidos pelo Estado que se podem obter melhores serviços e uma maior eficiência na aplicação dos recursos públicos.” (CAMARGO, 1997, p. 265). Nessa linha de argumentação, a democracia na escola se sustenta na idéia de que "todos os envolvidos no processo pedagógico têm capacidade de representar seus próprios interesses e de regular seus atos por iniciativa própria." (HABERMAS, 1986b, p. 920).

E, além disso, pressupõe que:

- o poder e a tomada de decisões devem ser compartilhados por alguns ou por todos os membros da organização;

- existe um conjunto de valores e de objetivos comuns que são compartilhados por todos os integrantes;

- todos os membros da organização têm uma representação formal nos órgãos de decisão;

- a organização deve determinar políticas e tomar decisões através de processos de discussão guiados pelo consenso. (GUERRA, 1994, p. 183). 
Em resumo, os mecanismos da gestão democrática, como os conselhos escolares, são importantes instrumentos a serviço da ampliação da participação social. Todavia, a sua simples existência e mesmo funcionamento formal não garantem que a força dos argumentos prevaleça sobre o argumento da força (HABERMAS, 1990). A disposição ao diálogo e à alteridade é determinante para a transposição da técnica e à consecução do princípio democrático.

\section{A função e os problemas dos conselhos de escola}

Os conselhos de escola são, em tese, os locais onde é capaz de se dar voz a quem não tem voz (CAMARGO, 1997, p. 291), isto é, são espaços potenciais do diálogo, da ação comunicativa. Os conselhos de escola como "fóruns de discussão e deliberação nascem não de um ato de vontade de um grupo de indivíduos que lutam por justiça ou liberdade, mas como uma necessidade que encontra seus fundamentos nos próprios processos de racionalização societária.” (PINTO, 1994, p. 153). José Marcelino de Rezende Pinto observa que a escola é uma instituição que está compartimentalizada num formato sistêmico de gestão e que teve padronizados os seus processos de tomada de decisões à luz de uma razão não comunicativa, não dialogada. A conversa aberta e franca entre os sujeitos individuais e coletivos, em uma instituição voltada à formação dos homens e mulheres, é pré-condição, segundo o autor, para a democratização da sua gestão, levando-nos a crer que o diálogo é condição de superação social ou, conforme Habermas, essa condição está vinculada ao desenvolvimento de uma ação comunicativa que está presente

sempre que as ações dos agentes envolvidos são coordenadas, não através de cálculos egocêntricos de sucesso mas através de atos de alcançar o entendimento. $\mathrm{Na}$ ação comunicativa os participantes não estão orientados primeiramente para o seu próprio sucesso individual, eles buscam seus objetivos individuais respeitando a condição de que podem harmonizar seus planos de ação sobre as bases de uma definição comum de situação. Assim, a negociação da definição de situação é um elemento essencial do conhecimento interpretativo requerido 
pela ação comunicativa. (HABERMAS, 1986a, p. 280).

É nesse sentido que os conselhos de escola têm dinâmicas que se valem da ação comunicativa (PINTO, 1994, p. 98). Todavia, os estudos empíricos sobre os conselhos, mesmo que confirmem essa disposição potencial ao diálogo, reconhecem que são instituições nas quais há uma compreensão limitada sobre as suas potencialidades políticas ou técnicas.

Os familiares dos alunos não observam os conselhos como instrumentos de poder, mas como organismos auxiliares na organização e gestão escolar (PINTO, 1994, p. 107). Talvez por conta disso os pais não ocupem com mais disposição seus lugares ali: "A experiência tem demonstrado que, não só os pais não têm assumido posições muito específicas dentro do conselho de escola, como o órgão em si não tem representado um contrapoder como alguns suspeitavam.” (SÁ, 2004, p. 134). E isso encerra um duplo problema: de uma parte, o potencial comunicativo e dialógico do conselho fica comprometido, de outra, e ainda mais grave, os familiares dos alunos, pela incompreensão que têm do potencial do conselho, tornam-se as primeiras vítimas da não consecução desse potencial, pois é especialmente para eles que o conselho foi criado, ou seja, é para garantir a presença dos seus olhares e vozes na condução da política escolar que mecanismos como os conselhos de escola foram constituídos.

É certo também que a constituição desses conselhos não está articulada apenas aos interesses democráticos da gestão, mas há um interesse técnico (que também não deixa de ser político) em parte considerável dos procedimentos de reformas educacionais que incentivam a criação de órgãos coletivos de gestão na escola, pelo menos da parte de quem propõe essas reformas. Esse interesse técnico se articula a uma idéia de que mecanismos dessa natureza poderiam viabilizar uma espécie de controle sobre a escola, com vistas ao desenvolvimento do accountability $^{2}$ (DARLING-HAMMOND; ASCHER, 2006). Isto é, é uma percepção de que os conselhos de escola poderiam significar uma diminuição do poder da corporação docente no controle do poder escolar, pois a presença dos pais e familiares dos alunos nesses conselhos representaria a figura do cliente ${ }^{3}$ ou usuário ou cidadão que tem a tarefa de cobrar resultados da escola.

Contudo, Sá (2004, p. 134), na esteira de Golby, afirma que 
esta expectativa assenta numa concepção restrita de poder, segundo a qual para que uns ganhem outros têm de perder. A esta teoria da soma zero do poder, que pressupõe que este deve ser entendido como uma quantidade finita, o que implica que quantos mais dele partilham menor fatia cabe a cada um, deve contrapor-se uma visão alternativa que admite que a partilha de uma esfera de acção com outros actores sociais pode resultar no reforço da capacidade de intervenção do novo colectivo.

Ademais, "alguns dados de investigações realizadas no âmbito dos conselhos de escola apontam mais para relações de cooperação entre a escola e os pais do que de competição ou de conflito.” (SÁ, 2004, p. 134). Salvo situações esporádicas, ou casos muito específicos, normalmente os familiares dos alunos se consideram aliados da escola ${ }^{4}$ e se dispõem a contribuir naquilo que as pessoas que trabalham na escola definem e o fazem "valendo-se de processos comunicativos com o intuito de alcançar o entendimento sobre algo confiando na força do bom argumento.” (PINTO, 1994, p. 137). Em resumo, isso quer dizer que "os pais não foram a 'espinha atravessada na garganta' dos professores que o ministério aparentemente esperava e não assumiram o papel de polícias da escola ao serviço do governo que lhes parecia estar reservado.” (SÁ, 2004, p. 135).

Mas, além dos administradores dos sistemas de ensino e reformadores da educação, a escola também olha para o conselho como uma ferramenta técnica ao seu dispor, comumentemente lançando mão dessa instituição "quando se trata de repartir o ônus que ninguém quer carregar” (PINTO, 1994, p. 138), como são os casos dos conselhos convocados a se reunirem para tratar de formas de a escola se livrar de alunos por ela indesejados. A pressão, normalmente do sistema de ensino, sobre o dirigente escolar é elevada em casos dessa natureza. Dividir as responsabilidades ou, se possível, transferi-las integralmente a um organismo coletivo, como o conselho, parece ser uma saída interessante na visão dos dirigentes escolares.

Em qualquer dos casos, o conselho de escola é uma instituição que está presente em parte considerável das escolas públicas brasileiras ${ }^{5}$ e conta com alta aprovação sobre o mérito da sua constituição: 
O potencial que primeiro salta aos olhos é o potencial de aprovação que um conselho de escola, funcionando com todas as suas vicissitudes, desperta em seus integrantes. Há um consenso praticamente absoluto quanto à superioridade do conselho de escola frente às formas burocráticas de gestão da escola. As críticas que surgem ao seu funcionamento decorrem, não de sua existência, mas sim por ele não atingir, na prática, suas potencialidades plenas (PINTO, 1994, p. 148).

Essa limitação das potencialidades do conselho de escola pode decorrer de diversos motivos. Carmargo (1997, p. 116) destaca um desses motivos ao afirmar que as decisões do conselho "não são soberanas no pleno sentido de sua autonomia, pois existe no setor educacional e nos sistemas públicos extensa série de leis e normas sobre o seu funcionamento." Parece-nos, contudo, que essa conclusão do autor pode ter mais sentido em alguns sistemas de ensino do que em outros ${ }^{6}$, uma vez que tanto em legislação nacional (LDB), quanto nas normativas de alguns estados não há necessariamente excesso de definição legal sobre o funcionamento, objeto e objetivos do conselho de escola.

Outros dois aspectos importantes para se avaliar as potencialidades do conselho de escola dizem respeito à representatividade dos conselheiros e à imperatividade do voto nos processos de tomada de decisões e nos demais posicionamentos:

A representatividade proporciona uma espécie de legitimidade para o representante tomar as decisões pelos seus representados, seja num conselho de escola ou em qualquer nível do poder legislativo, por conta de seus posicionamentos, sua história anterior, seu poder de oratória ou convencimento, ou ainda por sua exposição clara de seu projeto de trabalho [...] como representante e que oferece, a quem o elegeu, a garantia de que os compromissos assumidos publicamente serão respeitados. A imperatividade implica a vinculação do posicionamento do representante a determinado segmento escolar [...], e qualquer que seja a matéria a ser observada 
pelo representante, seu posicionamento já estaria previamente determinado. (CAMARGO, 1997, p. 118, 177).

Camargo avalia que a diminuição da distância e a ampliação dos contatos entre representantes e representados ${ }^{7}$, tanto no conselho de escola como na vida política na sociedade, poderiam dirimir problemas decorrentes desses dois aspectos. Parece muito presente nas escolas e entre os conselheiros uma concepção que aposta na necessidade de mandatos dos representantes vinculados imediatamente aos interesses dos segmentos que representam (SOUZA, 2002). Todavia, a representação política na prática tende a se pautar pelas compreensões e idéias próprias dos representantes (SOUZA, 2001), o que se, em um sentido é um problema - uma vez que os interesses diretos dos representantes aparecem com mais dificuldades nas reuniões e tomadas de decisões do conselho -, de outra parte, há um aspecto interessante nessa aparente independência dos representantes, pois podem se sentir livres para se posicionarem em favor dos interesses mais amplos da escola, a despeito das visões dos segmentos que representam, os quais, de sua parte, podem apresentar, em algumas situações, posições mais estreitas e, assim, danosas à gestão da escola.

Os problemas do conselho de escola são, a bem da verdade, bem mais amplos que esses três tópicos destacados. Em extenso levantamento, Camargo sintetiza diversos aspectos e os organiza, na esteira de Vítor Paro, em quatro condicionantes: materiais, ideológicos, institucionais e políticosociais. Esses condicionantes apresentam aspectos que determinam o (não) funcionamento adequado do conselho de escola. ${ }^{8}$ 


\begin{tabular}{|l|l|}
\hline \multicolumn{1}{|c|}{ Materiais } & \multicolumn{1}{|c|}{ Ideológicos } \\
\hline $\begin{array}{l}\text { Falta de horários comuns dos participantes } \\
\text { para as reuniões; }\end{array}$ & $\begin{array}{l}\text { Falta de percepção de interesses sociais } \\
\text { comuns entre os participantes do CE; }\end{array}$ \\
\hline $\begin{array}{l}\text { Falta de espaços para se fazer as } \\
\text { reuniões; }\end{array}$ & $\begin{array}{l}\text { "Participar" significando "ouvir" e } \\
\text { concordar com tudo o que se fala; }\end{array}$ \\
\hline $\begin{array}{l}\text { Falta de espaço para comunicar decisões } \\
\text { do CE (mural, jornal, circulares etc.); }\end{array}$ & $\begin{array}{l}\text { Falta de autonomia para implementar } \\
\text { idéias próprias; }\end{array}$ \\
\hline $\begin{array}{l}\text { Problemas de multiplicação de materiais } \\
\text { de formação de todos os representantes } \\
\text { dos segmentos do CE; }\end{array}$ & Medo do conflito e das contradições; \\
\hline $\begin{array}{l}\text { Falta de materiais e outros recursos para } \\
\text { chamar a comunidade à participação na } \\
\text { escola (ex.: cinema, teatro, festas etc.); }\end{array}$ & $\begin{array}{l}\text { Resultado regular na participação e } \\
\text { discussão no conselho de escola; }\end{array}$ \\
\hline Auxílios da comunidade são poucos; & Representatividade; \\
\hline $\begin{array}{l}\text { Organização do tempo de reunião e e } \\
\text { demais atividades; }\end{array}$ & $\begin{array}{l}\text { Conselho para decidir as questões da } \\
\text { escola; }\end{array}$ \\
\hline $\begin{array}{l}\text { Conselho de Escola e discussões sobre } \\
\text { orçamento; }\end{array}$ & $\begin{array}{l}\text { Conselho para superar uma visão } \\
\text { corporativista; }\end{array}$ \\
\hline Documentos em linguagem adequada; & Na hora de decidir, decide quem sabe...; \\
\hline $\begin{array}{l}\text { Problema do tempo para participar do } \\
\text { conselho. }\end{array}$ & $\begin{array}{l}\text { Medo dos pais e alunos de participarem } \\
\text { no Conselho por não entenderem os } \\
\text { "assuntos da escola"; }\end{array}$ \\
\hline $\begin{array}{l}\text { Difícil discussão do pedagógico no } \\
\text { Conselho. }\end{array}$ \\
\hline
\end{tabular}

\begin{tabular}{|l|l|}
\hline \multicolumn{1}{|c|}{ Institucionais } & \multicolumn{1}{|c|}{ Político-Sociais } \\
\hline $\begin{array}{l}\text { Escola pode ser vista enquanto espaço de } \\
\text { participação organizada; }\end{array}$ & $\begin{array}{l}\text { Dificuldade de explicar aos pais dos } \\
\text { alunos os conteúdos e processos } \\
\text { pedagógicos; }\end{array}$ \\
\hline $\begin{array}{l}\text { Processos de eleições do CE (dificuldade } \\
\text { imposta pelos prazos, calendários etc.); }\end{array}$ & Não conhecimento da realidade local; \\
\hline $\begin{array}{l}\text { Problema da freqüência nas reuniões do } \\
\text { CE; }\end{array}$ & Participação pró-forma; \\
\hline $\begin{array}{l}\text { Alguns avanços observados em aspectos } \\
\text { pedagógicos; }\end{array}$ & $\begin{array}{l}\text { Dificuldade em encontrar pessoas para } \\
\text { fazerem parte do CE; }\end{array}$ \\
\hline $\begin{array}{l}\text { Dificuldade do conselho na elaboração } \\
\text { do plano escolar; }\end{array}$ & $\begin{array}{l}\text { Mães e pais têm medo de interferir na } \\
\text { escola e os filhos sofrerem represálias dos } \\
\text { professores, diretor e demais funcionários; }\end{array}$ \\
\hline Necessidade de se conhecer a legislação; & $\begin{array}{l}\text { Dificuldade do conselho para interferir } \\
\text { nas questões pedagógicas da escola; }\end{array}$ \\
\hline
\end{tabular}


continuação de

\begin{tabular}{|l|l|}
\hline $\begin{array}{l}\text { Decorrências da institucionalização dos } \\
\text { conselhos. }\end{array}$ & $\begin{array}{l}\text { Participação dos pais dentro de certos } \\
\text { limites; }\end{array}$ \\
\hline & $\begin{array}{l}\text { Diferentes visões (de professores) } \\
\text { presentes no conselho; }\end{array}$ \\
\hline & Percepção do papel do diretor. \\
\hline
\end{tabular}

Quadro 1 - Condicionantes da organização e funcionamento do conselho de escola

Fonte: Camargo (1997, p. 303).

Alguns desses problemas são apontados por outros autores (PINTO, 1994; CISESKI ; ROMÃO, 1997; GUERRA, 1994; PARO, 1995), mas chamamos a atenção para quatro itens:

- dificuldades referentes à comunicação entre os conselheiros e entre o conselho e a comunidade escolar;

- compreensão de que a participação se esgota apenas na presença dos indivíduos;

- problemas com a institucionalização do conselho;

- dificuldades do conselho em interferir em questões de natureza pedagógica.

Todos esses problemas que foram, de alguma forma, destacados encontramse no levantamento da pesquisa de Camargo e se articulam, ao que parece, com os mais importantes elementos para a democracia escolar: A comunicação efetiva entre as pessoas pressupõe as condições básicas para se operar a democracia na escola; a participação democrática prevê uma ação intencional e ativa dos sujeitos; a democracia exige constante reflexão sobre os processos e técnicas para o diálogo, evitando-se a transformação da técnica na principal razão para o encontro entre as pessoas; os processos de gestão escolar não podem, em qualquer hipótese, perder de vista os objetivos educacionais centrais e a natureza e a função pedagógica da escola.

É verdade que a simples existência dos conselhos já foi um passo significativo para a construção da autonomia escolar, ${ }^{9}$ mas a potencialidade democrática dos conselhos só se verifica no desenrolar das suas práticas efetivas, nas quais se pode ou não confirmar tal vocação (GOHN, 2001, p. 107-108). 
Os conselhos de escolas são espaços contraditórios e destinados à expressão da contradição que lhes é inata: de uma parte, como espaço coletivo favorece o surgimento/afloramento dos conflitos institucionais e educacionais e, de outra parte, como espaço institucional dispõe do potencial de articulação de soluções locais para esses conflitos nos limites das suas possibilidades (CAMARGO, 1997, p. 349). Ou ainda,

Tanto podem alavancar o processo de participação sociopolítica de grupos organizados, como estagnar o sentimento de pertencer de outros - se monopolizados por indivíduos que não representem, de fato, as comunidades que os indicaram/elegeram. Eles [os conselhos] não substituem os movimentos de pressão organizada de massas, ainda necessários para que as próprias políticas públicas ganhem agilidade. (GOHN, 2001, p. 108).

Para funcionar não podem "ser vistos [...] como braços auxiliares do executivo, nem como substitutos da participação popular em geral." (GOHN, 2001, p. 94). E, "se representativos, os conselhos poderão alterar progressivamente a natureza do poder local. À medida que eles se tornem atuantes, fiscalizadores das ações do poder público [...], eles estarão construindo as bases de uma gestão democrática." (GOHN, 2001, p. 108109), mas, para tanto, não podem se posicionar como instâncias meramente consultiva e opinativa, "devem ter a capacidade e poderes normativos de decisão.” (GOHN, 2001, p. 111).

Os conselhos de escola, positivamente e sinteticamente:

- têm contribuído com a sensibilização da opinião pública sobre a importância e a complexidade do fato educativo;

- têm desenvolvido ações que têm tornado possível o aumento da transparência na gestão econômica das escolas e na eliminação progressiva de ações autocráticas;

- têm posto às claras, em muitos casos, as interioridades da escola, contribuindo portanto a um melhor conhecimento da realidade institucional por parte de todos os membros da comunidade educativa;

- têm aberto e desenvolvido uma via de informação. (GUERRA, 1994, p. 185). 
Ademais, demonstraram capacidade de:

- apoiar reivindicações e solicitações da escola à administração do sistema de ensino e aos poderes públicos, em geral;

- possibilitar a apresentação de ideias dos pais e alunos que não eram comuns entre os professores;

- normalizar o fato de que os membros da comunidade escolar entrem nas escolas;

- assumir as decisões mais comprometidas a respeito da disciplina dos alunos. (GUERRA, 1994, p. 185).

Apesar desses aspectos positivos, Miguel A. Santos Guerra também vê problemas no funcionamento dos conselhos, como discutido na classificação de Camargo. Desde disputas mal colocadas de interesses entre os diferentes segmentos, apatia ante a participação, confusão acerca das funções do conselho e dos conselheiros, sensação de inoperância, má organização das reuniões, burocratização do funcionamento do conselho e confusão epistemológica (GUERRA, 1994, p. 188-190). O autor espanhol assinala a importância dos problemas atinentes à existência de conselheiros submissos à direção escolar e ao dirigismo explícito ou não das reuniões e ações dos conselhos. Essa relação entre conselho e diretor escolar é talvez a mais complexa barreira para a construção/ampliação de ações mais democráticas na escola. Mendonça (2004, p. 288) faz uma avaliação aparentemente contrária:

Considerando que os colegiados [conselhos] têm um papel importante na direção coletiva da escola, o pequeno peso que exercem na deliberação de questões de natureza administrativa parece romper a forte tradição da escola brasileira de conferir à direção um papel fundamentalmente voltado para atividades ligadas a esta dimensão da vida da escola.

O que o autor parece deixar escapar é que se os conselhos não discutem as questões de natureza administrativa é porque quem define o que é a sua pauta de debates, o diretor, assim age movido por alguma intenção, a qual pode derivar do fato de talvez não desejar compartilhar com os conselheiros o domínio sobre tais temáticas. 
Portanto, parece haver uma relação de dependência entre o conselho e o diretor ${ }^{10}$, o que quer dizer que se a constituição dos conselhos representou um avanço na democratização das relações escolares, a concretização deste e outros passos depende em grande parte do posicionamento, inclusive pessoal, dos dirigentes escolares, dado que "mudanças na direção sempre repercutem de forma imediata no funcionamento do conselho de escola ou de qualquer outra atividade desenvolvida na escola." (PINTO, 1994, p. 155). Isto é, a direção escolar representa muito para a manutenção ou para a superação desse quadro, pois que também é ela mesma uma ferramenta da gestão escolar, porém central da política escolar.

\section{Notas finais}

A democracia, para se constituir como cultura, cobra um tributo de tempo que demanda paciência e insistência:

A participação exige um tributo de tempo que muitas vezes não se está disposto a pagar. A organização se converte então em um obstáculo para a democratização. Se aceita a teoria, se manifesta a vontade de participação, se desenvolvem as atitudes de abertura, mas não se pode levar à prática um modelo de gestão democrática. (GUERRA, 2000, p. 48).

A dinâmica presente no dia-a-dia das escolas provoca uma ansiedade na solução dos problemas perfeitamente compreensível. E essa dinâmica e ansiedade, por vezes, implicam em tomadas de decisões mais centralizadas e menos dialogadas. O conselho de escola acaba esquecido. Em algumas escolas as pessoas que respondem pela direção sentem certo receio de permitir que o conselho se efetive concretamente por supor que ele pode indispor a estrutura de poder presente no estabelecimento de ensino (SOUZA, 2001). Classicamente, a comunidade escolar reconhece na diretora da escola a sua principal autoridade e a possibilidade de modificar essa ideia, plantando elementos de uma cultura mais democrática, na qual o sujeito coletivo representado pelo conselho seria, este sim, a grande autoridade política, não encontra simpatia em parte dos dirigentes escolares. 
Quando a direção da escola não obsta o trabalho do conselho, ainda se encontra resistências no quadro de professores. Parece haver uma espécie de reserva de mercado para a gestão escolar. (SOUZA, 2001). Vale dizer, a possibilidade de socialização do poder (e, antes, de disputa pelo poder) provocada pelo conselho poderia trazer para o ambiente de decisão de maneira mais enfática a presença de pessoas (e diferentes opiniões) provenientes de outros segmentos que não o de professores, e isto parece incomodar parte dos docentes, historicamente aculturados na condição de grupo dominante na escola.

Este artigo mostrou algumas das possibilidades, bem com dos limites, para a ampliação da democracia na gestão escolar no que concerne à organização dos conselhos de escola. A literatura que trata dos conselhos é crescente no Brasil, fruto da ampliação da existência e peso deste organismo na organização e gestão escolar. Todavia, parece que a literatura ainda lida muito com o potencial dos conselhos em uma perspectiva de acreditar (ter fé!) na idéia de que instrumentos desta ordem podem modificar as bases sobre as quais as escolas públicas funcionam. Mesmo nós nos debruçamos aqui sobre isto, articulando a teoria com leituras sobre os limites e possibilidades dos conselhos. Resta à pesquisa na área buscar conhecer melhor a realidade complexa (com avanços e limitações) na qual conselhos, conselheiros e escolas estão inseridas, contribuindo para a desconstrução de mitos, como o do participacionismo, por exemplo.

E, por fim, e na linha de se perspectivar alternativas, é possível afirmar que a superação dos problemas elencados e o aumento do potencial comunicativo e democrático dos conselhos se colocam diretamente proporcionais à ampliação da mencionada cultura de participação. A necessária "pavimentação" do acesso dos alunos e seus familiares e dos funcionários não-docentes, somando-se aos professores e dirigentes, para as principais instâncias de gestão da escola depende de esforços multidirecionais, ou seja, todos têm de auxiliar na aproximação dos sujeitos dos diversos segmentos que compõem a escola e desenvolver aquela paciência ativa de, ao mesmo tempo, investir cotidianamente na organização das instâncias coletivas e compreender que a constituição de uma cultura democrática demanda tempo. 


\section{Notas}

1 “Os sistemas de ensino definirão as normas da gestão democrática do ensino público na educação básica, de acordo com as suas peculiaridades e conforme os seguintes princípios: I - participação dos profissionais da educação na elaboração do projeto pedagógico da escola; II - participação das comunidades escolar e local em conselhos escolares ou equivalentes." (BRASIL, 1996).

2 O accountability representa a constituição de mecanismos de responsabilização ou de controle sobre as ações públicas, escolares em especial. Há diferentes formas de accountability, segundo Darling-Hammond e Ascher (2006): político, legal, burocrático, profissional e de mercado. No caso do conselho de escola como um mecanismo de controle, quando assim pensado pelos reformadores e administradores dos sistemas de ensino, parece que se trata de uma forma de accountability político, de um lado, e de mercado, de outro. Para críticas ao accountability vide Robert (2006); Lissovoy e Mclaren (2003).

3 No caso do accountability de mercado a tarefa é a de cobrar pela qualidade dos serviços/produtos e, dessa forma, controlar a ação do prestador do serviço (a escola).

4 Mesmo quando o assunto em pauta em uma reunião de conselho é, por exemplo, a greve dos professores, assunto espinhoso e que compromete toda a organização da família (PINTO, 1994).

5 Em 2003, 87,5\% das escolas públicas informavam que tinham Conselho de Escola constituído (SOUZA, 2007).

6 Em sua tese de doutorado Camargo (1997) discute, dentre outros aspectos, o conselho de escola na cidade de São Paulo.

7 Paro (1995, p. 149) com ele concorda: "Um dos principais problemas que impedem que o conselho de escola se transforme num instrumento de democratização das relações no interior da escola é a falta de ligação entre representantes e representados, especialmente no que se refere a pais e alunos."

8 Aqui são apresentados apenas alguns dos itens desenvolvidos por Camargo (1997). 
9 A concepção de autonomia apenas mencionada remete a um debate mais complexo, certamente. Para maiores informações sobre a autonomia escolar ver Azanha (1987), Rios (1995), Barroso (1996) e Souza (2003).

10 "Os depoimentos [da pesquisa] indicam a total dependência do conselho de escola frente à figura do diretor” (PINTO, 1994, p. 140).

\section{Referências}

ADORNO, T.; HORKHEIMER, M. Dialética do esclarecimento. São Paulo: Jorge Zahar, 1985.

AZANHA, J. M. P. Educação: alguns escritos. São Paulo: Companhia Editora Nacional, 1987. (Atualidades Pedagógicas, v. 135).

BARROSO, J. O estudo da autonomia da escola: da autonomia decretada à autonomia construída. In: BARROSO, J. (Org.) O estudo da escola. Porto: Porto, 1996.

BRASIL. Presidência da República. Subchefia para Assuntos Jurídicos. Lei 9.394/96, Lei de Diretrizes e Bases da Educação Nacional, de 20 de dezembro de 1996. Estabelece as diretrizes e bases da educação nacional. Brasília, 1996. Disponível em: < http://portal.mec.gov.br/sesu/arquivos/ pdf/lei9394.pdf>. Acesso em: 1 abr. 2009.

CAMARGO, R. B. Gestão democrática e nova qualidade de ensino: o conselho de escola e o projeto de interdisciplinaridade nas escolas municipais da cidade de São Paulo (1989-1992). 1997. Tese (Doutorado em Educação)Faculdade de Educação. Universidade de São Paulo, São Paulo, 1997.

CISESKI, Â. A.; ROMÃO, J. E. Conselhos de Escola: coletivos instituintes da Escola Cidadã. In: GADOTTI, M.; ROMÃO, J. E. (Org.). Autonomia da escola: princípios e propostas. São Paulo: Cortez, 1997.

DARLING-HAMMOND, L.; ASCHER, C. Construindo sistemas de controle em escolas urbanas. Estudos em Avaliação Educacional, São Paulo, v. 17 , n. 35, p. 7-48, set./dez. 2006.

GOHN, M. G. Conselhos gestores e participação sociopolítica. São Paulo: Cortez, 2001. 
GUERRA, M. A. Santos. Entre bastidores: el lado oculto de la organización escolar. Málaga: Aljibe, 1994. . La escuela que aprende. Madri: Morata, 2000.

GUTIERREZ, G. L.; CATANI, A. M. Participação e gestão escolar: conceitos e potencialidades. In: FERREIRA, N. S. C. (Org.). Gestão democrática da educação: atuais tendências, novos desafios. São Paulo: Cortez, 2000.

HABERMAS, J. Soberania popular como procedimento. Novos estudos Cebrap, São Paulo. n. 26, p. 100-113, mar. 1990.

Teoria dell'agire comunicativo: I, Razionalità nell'azione e razionalizzazione sociale. Bologna: Il Mulino, 1986a.

Teoria dell'agire comunicativo: II, critica della raggione funzionalistica. Bologna: Il Mulino, 1986b.

LISSOVOY, N.; McLAREN, P. Educational "accountability" and the violence of capital: a marxian reading. Journal of Education Policy, Londres, v. 18, n. 2, p. 131-143, 2003.

MENDONÇA, E. F. A regra e o jogo: democracia e patrimonialismo na educação brasileira. Campinas: FE/UNICAMP, 2004.

NUNES, A. C. Gestão democrática ou compartilhada? uma (não) tão simples questão de semântica. Cadernos Pedagógicos, Curitiba, n. 2, p. 37-40, mar. 1999.

PARO, V. Administração escolar: introdução crítica. 3. ed. São Paulo: Cortez, 1988.

. Por dentro da escola pública. São Paulo: Xamã, 1995.

PINTO, J. M. R. Administração e liberdade: um estudo do conselho de escola à luz da ação comunicativa de Jürgen Habermas. 1994. Tese (Doutorado em Educação)- Faculdade de Educação. Universidade Estadual de Campinas. Campinas, 1994.

RIBEIRO, J. Q. Ensaios de uma teoria da administração escolar. São Paulo: USP, 1952.

RIOS, T. A. A autonomia como projeto: horizonte ético-político. In: BORGES, A. et al. (Org.) A autonomia e a qualidade do ensino na escola pública. São Paulo: FDE, 1995. (Série Ideias, 16). 
ROBERT, B. Equity in the implementation of accountability policies in education. In: CONGRESSO MUNDIAL DE SOCIOLOGIA, 16., 2006, Durban, África do Sul. Anais... Durban, África do Sul: ISA, 2006.

SÁ, V. A participação dos pais na escola pública portuguesa: uma abordagem sociológica e organizacional. Braga, Portugal: IEP/Universidade do Minho, 2004.

SOUZA, A. R. A formação do conselheiro de escola: construindo a democracia. In: CONGRESSO NACIONAL DE EDUCAÇÃO, 4., 2001, São Paulo. Anais... São Paulo: CONED, 2001.

- A democratização da gestão educacional. In: GOUVEIA, Andréa et al. Seminários temáticos 2: curso de pedagogia, séries iniciais do ensino fundamental na modalidade de educação à distância. Curitiba: UFPR/NEAD, 2002.

. Reformas educacionais: descentralização, gestão e autonomia escolar. Educar em Revista, Curitiba, n. 22, p. 17-50, jul./dez. 2003.

Perfil da gestão escolar no Brasil. 2007. Tese (Doutorado em Educação) - Pós-Graduação em Educação. Pontifícia Universidade Católica de São Paulo, São Paulo, 2007.

TEIXEIRA, A. Que é administração escolar? Revista Brasileira de Estudos Pedagógicos, Rio de Janeiro, v. 36, n. 84, 1961. p. 84-89.

. Educação no Brasil. Rio de Janeiro: Editora UFRJ, 1999.

WEBER, M. Economia y sociedad: esbozo de sociologia comprensiva. México: FCE, 2004. 


\section{School council: functions, problems and perspectives in democratic school management}

\begin{abstract}
:
This article has a bibliographic nature and discusses the democratic problems and perspectives for school councils. The study first discusses the problems of "mythification" of technique in the constitution and use of school management organizing mechanisms. The text then demonstrates how the democratic functions and potential of the school council counter the daily difficulties to constitute, maintain and develop collective spaces of management, demonstrating how much the councils are, in principle, spaces of dialog, and at the same time, how far they are from effectively exercising their democratic function. The conclusions point to the important recognition of the existing limits in the formulation and organization of school councils, but, at the same time suggest the need to insist on the maintenance and perfection of the councils because they represent a significant contribution for democratic school management.
\end{abstract}

Key words: Education councils. Schools - Organization and administration.

\section{Consejos de escuela: funciones, problemas y perspectivas en la gestión escolar democrática}

\section{Resumen:}

El artículo, de naturaleza bibliográfica, discute los problemas y las perspectivas democráticas de los Consejos de escuela. En el texto se debate, primeramente, el problema de la mistificación de la técnica en la constitución y en el uso de mecanismos organizativos de la gestión escolar. En seguida, demuestra como las funciones y las potencialidades democráticas del consejo de escuela son contrapuestas frente a las dificultades cotidianas para la constitución, mantenimiento y desarrollo de los espacios colectivos de gestión, demostrando cuanto los consejos son, en principio, espacios de diálogo y, al mismo tiempo, cuán distante están de su función democrática. Las conclusiones apuntan para un importante reconocimiento de los limites existentes en la formulación y organización de los consejos de escuela, pero, al mismo tiempo, sugieren la necesidad de insistir en el mantenimiento y perfeccionamiento de los consejos ya que ellos contribuyen de manera significativa para la gestión escolar democrática.

Palabras-clave: Consejo de Educación. Escuela. Organización y administración. 


\section{Ângelo Ricardo de Souza}

Universidade Federal do Paraná, Setor de Educação Rua Gal. Carneiro, 460

Curitiba-PR

E-mail: angelo@ufpr.br

Recebido em: 8/4/2009

Aprovado em: 14/5/2009 